\title{
ANÁLISE DAS DIFICULDADES ORTOGRÁFICAS POR MEIO DE ANÁLISE DE PRODUÇÃO DE TEXTOS
}

\section{ANALYSIS OF ORTOGRAFPHIC DIFFICULTIES TROUGH THE ANALYSIS OF TEXT PRODUCION}

Célia Aparecida de Souza ${ }^{1}$ Joana Darc Pereira Brandão ${ }^{2}$ Christiane Renata Caldeira de Melo $^{3}$ https://doi.org/10.29327/216986.1.1-7

RESUMO: Este artigo tem como meio identificar as dificuldades de aprendizagem na escrita dos alunos do $5^{\circ}$ ano do ensino Fundamental de uma escola da rede pública. Para esta pesquisa, foram utilizados fundamentos de pesquisa qualitativa e como instrumento de coleta de dados questionários aos professores. É importante, nesse contexto, conhecer as dificuldades ortográficas de coerência e de coesão encontradas pelos alunos nas produções escritas e as estratégias utilizadas pelos professores para promover escrita conforme as normas da Língua Portuguesa, considerando a hipótese de que o aluno escreve como fala. Embasou-se, neste estudo, em autores como Pilastri (2009), Bernardino (2012), Cagliari (1990), Moraes (2002), Vygotsky (2002), Carneiro (2009), entre outros.

Palavras-chave: Aprendizado, dificuldade ortográfica, leitura, aquisição da escrita.

ABSTRACT: The spelling is an important means used by mankind for communication and writing production. This article has as a

\footnotetext{
${ }^{1}$ Licenciada do curso de Pedagogia EAD da Faculdade do Noroeste de Minas - FINOM. E-mail: ca.celia@hotmail.com

${ }^{2}$ Licenciada do curso de Pedagogia EAD da Faculdade do Noroeste de Minas - FINOM. E-mail: joana.1darc@outlook.com

${ }^{3}$ Mestra em Letras pela Universidade Federal de Uberlândia (UFU). É professora das disciplinas Comunicação e Expressão e Português Instrumental nas faculdades FINOM/TECSOMA, coordena o grupo de Pesquisas em Avaliação e Ética (GPAE), como bolsista do Núcleo de Iniciação Científica (NIP), 2018/2020. http://lattes.cnpq.br/3088053539279651 E-mail: christianemelo@finom.edu.br
} 
means to seek to identify learning disabilities in writing of the students of the 5th grade of elementary school to a public school. Was used qualitative research fundamentals and as an instrument of data collection questionnaires to teachers. Meet the orthographic difficulties of coherence and cohesion encountered by students in productions written and the strategies used by teachers to promote writing as the norms of the Portuguese Language, whereas the student writes like speaks. Being carried out the theoretical basis with literary review from authors such Pilastri (2009), Bernardino (2012), Cagliari (1990), Moraes (2002), Vygotsky (2002), Carneiro (2009), entre outros.

Keywords: learning, spelling, reading difficulty, acquisition of writing

\section{Introdução}

As dificuldades na produção escrita podem ser advindas da ausência, ou não hábito, da leitura e da escrita por parte do aprendiz. Para esta pesquisa, considera-se que o aprendiz não domina, ou ainda, não consolidou esses dois processos e passa por uma condição de desconhecimento das regras básicas de ortografia, bem como as relativas à construção de textos com coerência e coesão.

Assim, destaca-se a leitura como um exercício principal para a melhoria na produção escrita, pois um aluno que se habitua a ler, tem maior capacidade de organizar suas ideias e de forma natural e, por consequência, acaba por não observar as regras de ortografia.

Nesse sentido, a ortografia é um meio utilizado pela humanidade para a comunicação e a produção da escrita em diversas situações comunicativas, utilizada no dia a dia para suprir as necessidades de interação. Sob esse ponto de vista, acredita-se que capacidade de se ter uma boa escrita se deve ao ato de uma grande interação com a leitura e aqueles os quais não o têm, ao escreverem diversos gêneros textuais/discursivos com desvios de ortografia, desistem da produção textual. 
Nesse esse viés, parte-se da seguinte indagação: a). Por que os alunos do $5^{\circ}$ ano ainda têm tanta dificuldade na produção escrita? Essa é uma questão desafiadora é de grande importância, pois busca compreender as etapas do desenvolvimento do sistema escrito que não foram consolidados no processo de alfabetização e letramento de alguns aprendizes.

Outro fator salutar com relação aos possíveis desvios ortográficos é que avanço tecnológico e a banalização da linguagem na internet podem ocasionar uma crescente dificuldade na utilização da norma padrão da Língua Portuguesa por alunos do Ensino Fundamental inicial. A internet, desse modo, revolucionou o comportamento, as relações e o uso da norma padrão da Língua Portuguesa. Sendo assim, o uso dessa tecnologia fez com que surgissem novas maneiras de escrever e falar. Ademais, tal fato contribuiu para as dificuldades de leitura e escrita e, principalmente, fazer o aprendiz crer que está escrevendo certo quando suprime algumas letras das palavras.

Pensando nessas lacunas de ensino das produções textuais e da ortografia, os questionamentos que cercam este estudo são exatamente as dificuldades ortográficas que os alunos do $5^{\circ}$ ano têm ao escrever e analisar as estratégias mais adequadas a serem empregadas na solução desse problema.

Assim sendo, a pesquisa de campo foi realizada em uma escola pública com alunos e professores do $5^{\circ}$ ano do município. Nessa perspectiva, vale a pena questionar: a). Qual o sentido da alfabetização? B) Por que tantos alunos sentem dificuldade para ler e escrever? c) Para além do fenômeno do fracasso escolar, como explicar as distâncias entre as conquistas dos alunos supostamente bem-sucedidos e os apelos do nosso mundo? d)) Como as práticas de alfabetização podem contrariar a formação do sujeito autor e leitor? e) Até que ponto o ensino da língua escrita, no contexto da cultura escolar, configura-se como um esforço que não necessariamente amplia as relações entre o homem e o universo letrado? Essas indagações, ou melhor, inquietações motivaram esta pesquisa.

Nela, surgiu da necessidade de compreender os problemas da escrita para analisar quais estratégias usadas pelos professores para 
melhorar a produção escrita dos alunos, pois a aprendizagem é construída ao longo da vida e se há lacunas no processo de produção textual, essas devem ser analisadas.

\section{Dificuldades dos aprendizes}

O ensino brasileiro passa por momentos de grandes mudanças, desse modo, torna-se necessário conhecer e desvendar as dificuldades dos alunos na escrita, encontrado pelos alunos do Ensino Fundamental, visto que já vem estudando há alguns anos.

Sobre as dificuldades enfrentadas pelos alunos na escola, Carneiro (2009, p.10) lembra que na escola, a grande dificuldade enfrentada pelos alunos com relação à escrita refere-se à necessidade que eles têm em deixar a linguagem coloquial, aquela do dia-a-dia, e passar a se expressar, por escrito, numa linguagem formal e mais cuidadosa. A fala por ser espontânea menos cerimoniosa e, com certeza mais fácil de escrever, pelo simples fato de ter normas próprias (ortografia, acentuação, etc.), a falta de um interlocutor a sua frente exige delas que a obedeçam a essas normas.

Ressalta-se que para que o aprendiz tenha boas referências de produção de texto, é preciso aprender a escrever abandonando a linguagem no dia a dia, a norma não padrão da Língua Portuguesa, e, fazê-lo de forma mais elaborada e formal usando as normas da escrita e produzindo texto claro e coerente com o tema abordado em sala de aula pelo docente.

Muitos pesquisadores, entre eles, Emília Ferreiro e Ana Teberosky (1979), dedicaram-se à pesquisa do pensamento infantil sobre a leitura e a escrita. Por um lado, segundo elas, é preciso considerar que ao chegar à escola a criança não se depara com a linguagem escrita no primeiro dia de aula, porque nos diferentes contextos sociais em que vive independente da sua condição socioeconômica, este contato com a escrita existe de diferente forma.

Para Garcia (2002, p. 301), "aprender a ler e escrever é, em grande parte, se não principalmente, aprender a pensar, aprender a encontrar ideias e a concatená-las, pois, assim como não é possível dar o que não se tem, não se pode transmitir o que a mente não criou 
ou não aprisionou". Dessa maneira, é preciso sim exibir um texto esteticamente bonito, mas também se torna necessário aperceber-se do contexto em que o indivíduo que escreveu o texto está inserido, avaliando não só a estética do texto (visual), mas o sentido e a devida escrita das palavras (ortografia). Dessa maneira, uma maneira de aprimorar a escrita é estar concentrado naquilo que está produzindo (gêneros textuais/discursivos).

Além disso, há alunos que estudam em escolas que privilegiam a leitura e a escrita, mas estes vivem num contexto social diferente da maioria dos alunos que estudam em escolas públicas e vivem numa sociedade menos abastada. Assim, estes alunos são diferentes até no falar, pois estão acostumados com linguagem formal em seu dia a dia.

Para Soares (1992, p. 6) ocorre o seguinte:

O conflito entre linguagem de uma escola fundamentalmente a serviço das classes privilegiadas, cujos padrões linguísticos usam e querem ver usado, e a linguagem das camadas populares que essa escola censura é estigmatizada, é uma das principais causas do fracasso dos alunos pertencentes a essas camadas, na aquisição do saber escolar.

Nesses exemplos, cabe ao professor ser o mediador da norma culta de linguagem a alunos que falam e escrevem na informalidade das palavras para que não haja a dicotomia entre as duas formas de expressão (fala e escrita). No entanto, esta não é uma tarefa fácil para professores que dispõe de tempo limitado e alunos que convivem com diferentes linguagens em seu cotidiano. O importante é fazer com que o aluno exercite a escrita até aprender, ou melhor, assimilar que pode produzir textos melhores a cada dia.

Segundo os PCNs (1997, p. 87), "o trabalho com a memorização ortográfica deve estar contextualizado, basicamente, em situações em que os alunos tenham razões para escrever corretamente, em que a legibilidade seja fundamental porque existem leitores de fato para a escrita que produzem". A habilidade da escrita não se aprende repentinamente, torna-se necessário o uso da 
disciplina e da persistência, em elaborar e reelaborar a escrita até que se aprimorem as técnicas da linguagem.

Tal ensino em constância com as diretrizes curriculares implica a consciência de que o aluno precisa criar o hábito de ler e reler os textos que produzem na busca de encontrar erros. Morais (2002, p. 119) acrescenta, "vejo que muitas crianças e adolescentes não incorporam com a experiência escolar a atitude de "voltar ao que escreveram". Noto, muito frequentemente, que os alunos nem sequer releem seus textos". A reescrita seria uma prática adequada para minimizar as dificuldades do aprendiz.

Outra metodologia seria a consulta ao dicionário, uma vez que é necessário para conhecer o significado das palavras e sua escrita correta. Assim, para Morais ,2002, p. 11:

Se no domínio ortográfico o dicionário se presta especialmente para que avance em nossos conhecimentos sobre as irregularidades de nossa escrita, ele é sem dúvida uma fonte de saber sobre a linguagem que vai muito além do "escrever certo".

Ele pode ser usado como um objeto de conhecimento sobre o qual podemos ter curiosidade, duvidando, comparando, antecipando soluções. Por ser o português uma língua tão complexa, o aluno pode se valer do dicionário como aliado para sanar dificuldades ortográficas e buscar palavras que complemente o sentido da escrita de forma a não ser repetitivo nas palavras, desenvolvendo o texto com clareza.

Acredita-se que a escola precisa trabalhar com a ideia de que a semântica pode orientar a escrita correta e a escola precisa provocar nos sujeitos uma reflexão sobre a língua, pois um saber metalinguístico que relacione ortografia e significado poderá levar os sujeitos a um melhor desempenho da escrita convencional. Nesse sentido, o ensino da língua estimula a reflexão sobre as dificuldades ortográficas específicas e orienta o aluno no sentido de reconstruir a escrita. O professor, ao propor a atividade de produção da escrita, deve estimular o aluno a fazê-lo de maneira a avaliar hipóteses, confrontar ideias, discutir temas e fazer análise ortográfica para que 
ocorra o efetivo domínio das regras ortográficas de diferentes formas.

Para Pilastri (2009, p. 01) é preciso tomar cuidado com as linguagens da internet:

Atualmente, com as facilidades da internet, muitas pessoas estão se valendo da "arte de escrever", pois, em um momento em que é necessário se destacar, a escrita vem proporcionando visibilidade a muitos profissionais. Porém, é necessário um olhar mais atento a essa ferramenta de marketing, pois o seu texto pode falar muito sobre você e, principalmente, pode contribuir com uma má impressão profissional se você não tomar alguns cuidados.

Por outro lado, os professores sempre se preocupam em avaliar o que a criança sabe sobre linguagem que lhe é ensinada na escola, mas é preciso considerar que independente do que a escola ensina, esta criança deve ser avaliada no conhecimento que tem relativo à escrita. Desde antes de ingressar no contexto escolar a criança já vive em seu mundo, cercada de todos os tipos de representações, portanto já sabe reconhecer símbolos, objetos e signos.

Nesse sentido, já distinguem os desenhos corriqueiros de outras representações e buscam esboçar grafias que tentam se parecer com as letras, às vezes conseguem, às vezes, não, mas tentam. Logo perceberá a diferença entre os signos gráficos (desenhos, letras e números), mas irá usá-los de modo aleatório. Começa a ter uma noção maior da forma das letras, do alinhamento horizontal, da escrita da esquerda para direita e chega ao chamado momento evolutivo de ocupar a página, como todos signos misturados.

A habilidade da escrita não se aprende repentinamente, tornase necessário o uso da disciplina e da persistência, em elaborar e reelaborar a escrita até que se aprimorem as técnicas da linguagem. Assim sendo, o aluno precisa criar o hábito de ler e reler os textos que produz na busca de encontrar erros.

\section{A escrita na escola}

Educação In Loco, v.01, n. 01, jan.-jun. 2020 
A criança não aprende a ler e escrever de modo espontâneo, embora a espontaneidade infantil esteja sempre presente. No processo de alfabetização isso é muito significativo, porque apesar de todo o conhecimento da criança, a alfabetização é iniciada na escola por meio do acesso ao uso do sistema alfabetização (de uso do nosso idioma), que implica uma retomada de vários conceitos que auxiliarão no processo de aquisição da língua escrita. Tudo isso é proporcionado na/pela escola, utilizando-se obviamente do conhecimento que a criança traz com ela.

Dessa forma, cabe à escola no ensino da língua escrita, apresentar, vivenciar, trabalhar e discutir como criança os procedimentos de leitura e de escrita, com a finalidade de desenvolvimento na criança habilidade de construir os significados culturais e a sua capacidade comunicativa, por meio do uso correto da linguagem.

Cabe à escola e todos os envolvidos no processo, promoverem essa condição. Cunha (2005) analisa a questão:

Nossos alunos, ao entrarem na escola pela primeira vez, já trazem consigo seus conhecimentos sobre a língua, a escrita e a leitura. Cabe ao educador mudar sua concepção de que é ele quem vai ensinar todos estes universos à criança, ele irá sistematizar o conhecimento acumulado a partir das interações que aluno- cidadão vem desenvolvendo no passar dos anos (p. 42-43)

Refletindo sobre este assunto, a criança que não recebe estímulos dificilmente se desenvolverá, então é muito importante à família ajudar desde pequeno, ensinar a falar certo, pois quando for à escola já vai com esse conhecimento sobre a língua visando aprimorar a sua condição de comunicação, precisa desenvolver habilidades de leitura e de escrita, o que envolve diretamente a alfabetização.

Colello (2012) expõe e discute esses motivos. Segundo a autora, o ensino escola da língua materna, no Brasil, é reducionista. Ele se escora no pressuposto equivocado de que basta transmitir o

Educação In Loco, v.01, n. 01, jan.jun. 2020 
código alfabético e a norma gramática para fazer do aluno um escritor: depois de dominar o sistema notacional a aprendiz simplesmente transfere suas competências no uso da fala, para o exercício escrita. A escrita não é mera transcrição da fala, em situações reais de uso língua (quer dizer fora da ficção escolar) não se escreve, nem se fala, a não ser que haja algo a ser dito a alguém.

Ao tratar a língua como sistema, objeto de descrição das gramáticas isolado do uso, a escola traz essência interativa da linguagem (idem, p. 62), comprometendo, pois um lado, os processos de elaboração cognitiva das crianças, pois que estes dependem da relação do sujeito aprendiz como o(s) outros(s) e por outro lado a compreensão da natureza dialógica polifônica e responsiva da linguagem.

Assim, a autora sustenta que, na escola, uma concepção reducionista do objetivo de ensino articula-se a uma concepção reducionista do processo de ensino e a uma concepção reducionista da aprendizagem. Com o propósito de repensar as concepções acerca da língua, do ensino, da aprendizagem e das práticas pedagógicas, a escola recebe o professor como um depositário das regras gramaticais e textuais que, dada sua habilidade didática, seria capaz de transmitir aos alunos.

Vê-se que, desse modo, um bom redator precisa estar atento às armadilhas da linguagem, tomando os devidos cuidados com o que, para quem, porque, e como se escreve.

A revisão bibliográfica se torna necessária para que ocorra a coerência tão exigida na redação de textos e outros escritos. Diante desse problema, percebe-se a necessidade de compreender os problemas de aprendizagem na escrita apresentadas pelos alunos do $5^{\circ}$ ano. A educação ainda é a solução para muitos problemas da sociedade brasileira, mas ela sozinha se caracteriza em milagre. Esta deve ser associada ao aprendizado do dia a dia dos alunos e aos hábitos que este vai adquirindo no decorrer de sua vida. Nesse contexto, a escola precisa contar com os pais, comunidade e principalmente, com professores que sejam capazes de estimular a criação espontânea dos alunos. Sentindo capazes de desenvolver suas habilidades com liberdade de criação, os alunos serão capazes 
de surpreender, envolvendo na educação para a vida que todos querem.

Para Garcia (2002, p.301) "aprender a escrever, é em grande parte, se não principalmente, aprender a pensar, aprender a encontrar ideias e a concentrá-las, pois, assim como não é possível dar o que não se tem, não se pode transmitir o que a mente criou ou não aprisionou". Portanto na maneira de aprimorar a escrita é concentrar naquilo que está produzindo. Portanto, é preciso sim exibir um texto esteticamente bonito, mas também se torna necessário aperceber-se do contexto em que o indivíduo que escreveu o texto está inserido, avaliando não só a estética, mas o sentido e a devida escrita das palavras.

Teberosky (2008) afirma que para o aluno desenvolve a habilidade da escrita precisa haver sequências de atividades repetidas que giram em torno de leitura em voz alta, falar sobre o texto oralmente, fazer releitura e trabalhar a reescrita dos alunos. Durante todo processo de aprendizagem permanece a alternância de ler, falar e escrever. Com esses diferentes níveis de ensinamento os aprendizes desenvolvem competências para escutar e acompanhar a leitura e assim acaba adquirindo conhecimento sobre a linguagem e a escrita.

Mas para Vygotsky (1991), as dificuldades na escrita são um problema que não significa falta de capacidade de uma criança, mas sim, um problema em que ela tem o desenvolvimento da escrita obstaculizando por tipo de déficit. $\mathrm{O}$ desenvolvimento pode estar qualificativamente diferente e não mais lento ou inferior ao das outras crianças.

A linguagem escrita não se aprende repetidamente, tornando necessário o uso da disciplina e da persistência, em elaborar e reelaborar a escrita até que se aprimorem as técnicas da linguagem. Assim, o aluno precisa criar o hábito de ler e reler os textos que produz na busca de encontrar erros. Morais (2002, p. 119) acrescenta, "vejo que muitas crianças e adolescentes não incorporam com a experiência escolar a atitude de "voltar ao que escreveram". Noto, muito frequentemente, que os alunos nem sequer releem seus textos". 
A consulta ao dicionário também se torna necessária para conhecer o significado das palavras e sua escrita correta. Assim, para Morais (2002, p. 117).

Se no domínio ortográfico o dicionário se presta especialmente para que avancemos em nossos conhecimentos sobre as irregularidades de nossa escrita, ele é sem dúvida uma fonte de saber sobre a linguagem que vai muito além do "escrever certo". Ele pode ser usado como um objeto de conhecimento, um objeto sobre o qual podemos ter curiosidade, duvidando, comparando, antecipando soluções.

Por ser o português uma língua tão complexa, o aluno pode se valer do dicionário como aliado para sanar dificuldades ortográficas e buscar palavras que complemente o sentido da escrita de forma a não ser repetitivo nas palavras, desenvolvendo o texto com clareza, Morais (2002, p. 75) esclarece.

Acreditamos que a escola precisa trabalhar com a ideia de que a semântica pode orientar a escrita correta. A escola precisa provocar nos sujeitos uma reflexão sobre a língua, pois um saber metalinguístico que relacione ortografia e significado poderá levar os sujeitos a um melhor desempenho da escrita convencional.

Nesse sentido, o ensino da língua estimula a reflexão sobre as dificuldades ortográficas específicas e orienta o aluno no sentido de reconstruir a escrita. O professor ao propor a atividade de produção de escrita deve estimular o aluno a fazê-lo de maneira a avaliar hipóteses, confrontar ideias, discutir temas e fazer análise ortográfica para que ocorra o efetivo domínio das regras ortográficas.

Para Pilastri (2009, p.1) é preciso tomar cuidado com as linguagens dá-se que um bom redator precisa estar atento às armadilhas da linguagem, tomando os devidos cuidados com o que, para quem, porque, e como se escreve.

$O$ professor pode fomentar a criação do aluno por meio de estratégias que valorizem a escrita e que ajudem a compreensão de regras de redação sem, no entanto, parecer regras autoritárias.

Para Soares (1992, p.6) ocorre o seguinte: “(...) o conflito entre a linguagem de uma escola fundamentalmente a serviço das 
classes privilegiadas, cujos padrões linguísticos usam e quer ser usada, e a linguagem das camadas populares que essa escola censura é estigmatizada, é uma das principais causas dos fracassos dos alunos pertencentes a essas camadas, na aquisição do saber escolar".

\section{Resultados}

A pesquisa foi feita com professores do $5^{\circ}$ ano do ensino fundamental pela aplicação de questionários, de acordo com os objetivos deste estudo, foi analisado o porquê de o aluno ter tanta dificuldade com a ortografia, podendo assim distinguir o que falta para esse aprendizado e por qual motivo ele existe.

Em vista, podem-se observar quais aspectos são mais difíceis para as crianças aprenderem. Percebemos que a dificuldade ortográfica das crianças se deve ao ato de não de lerem e assim não escrevem corretamente.

Quadro 1: Questionário docente.

\begin{tabular}{|c|c|}
\hline Pergunta & Resposta \\
\hline 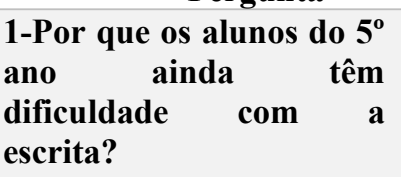 & $\begin{array}{l}\text { "Às vezes essa dificuldade na escrita se dá á } \\
\text { pelo fato deles queimarem etapas nas séries } \\
\text { iniciais, falta de atenção e não tem o hábito } \\
\text { da leitura (PROF I)". }\end{array}$ \\
\hline $\begin{array}{l}2-0 \text { que deve } r \text { ser } \\
\text { trabalhado com } \\
\text { crianças para que elas } \\
\text { desenvolvam? }\end{array}$ & $\begin{array}{l}\text { "Devem ser estimuladas a ler para } \\
\text { desenvolver a autonomia, trabalhar vários } \\
\text { tipos de textos (gêneros textuais), porque } \\
\text { através da leitura os alunos possam observar } \\
\text { como escreve as palavras que mais } \\
\text { encontram dificuldades" (PROF II). }\end{array}$ \\
\hline $\begin{array}{lr}\text { 3-Qual o objetivo } & \text { da } \\
\text { ortografia } & \text { no } \\
\text { aprendizado } & \text { das } \\
\text { crianças? } & \end{array}$ & $\begin{array}{l}\text { "Saber ler e escrever corretamente, } \\
\text { ampliando o vocabulário sabendo o } \\
\text { verdadeiro significado das palavras para } \\
\text { desenvolverem um melhor aprendizado } \\
\text { com qualidade". "Porque quando o aluno } \\
\text { escreve corretamente ele está apto a } \\
\text { interpretar o que leu e escreveu." (PROF I) }\end{array}$ \\
\hline $\begin{array}{l}\text { 4-Quais as maiores } \\
\text { dificuldades ortográficas }\end{array}$ & $\begin{array}{l}\text { "São as trocas de letras quando tem o } \\
\text { mesmo som. Dificuldade com relação às }\end{array}$ \\
\hline
\end{tabular}

Educação In Loco, v.01, n. 01, jan.-jun. 2020 


\section{das crianças?}

5-Quais os problemas que podem causar as dificuldades de aprendizagem da escrita nas séries iniciais e no ensino fundamental, e a quem podem ser atribuídos esses problemas?

\section{6-Com relação à situação} atual do ensino fundamental dos $5^{\circ}$ anos, o que pode ser feito para mudar a qualidade e melhorar aprendizagem?

7-Que ideia terá uma criança sobre o que é escrita?

\section{8-Qual é maior} dificuldade no processo do desenvolvimento da leitura escrita no ensino fundamental?

\section{9-O que devemos} fazer como professores a mudar essa situação? regularidades e irregularidades ortográficas" (PROF II)

"A falta de compromisso da família que não acompanha a vida escolar dos filhos, a falta de interesse dos alunos, e a falta de recursos apropriados para se trabalhar em sala de aula, atraso no processo de alfabetização e posteriormente prejuízo no futuro escolar do aluno". (PROF I)
"Mais investimento garantia de escolas, infraestrutura decente e profissional qualificado, uma alfabetização de qualidade seria melhor caminho para ensino fundamental melhor, a conscientizar os pais sobre importância da educação escolar para futuro dos seus filhos". (PROF II)

"O papel central que as práticas de leitura e escrita ganharam em nossa sociedade influencia o olhar das crianças e a realidade que os cercam mesmo antes de entrar na escola". (PROF II)

"É falta de materiais mais completos e falta dos pais para ficarem atentos com filhos com boa leitura, tirar eles mais da era da tecnologia que maioria atrapalha em seu desenvolvimento, pois eles usam de modo incorreto para sua aprendizagem, problema também começa com processo inadequado de alfabetização".(PROF I)

"Devemos contribuir por meio de atividades que levam a reflexão sobre a língua, sobre uso, criando significado que façam sentidos para criança, escola e professores devem criar novos contextos para aprendizagem da leitura e escrita, situações que valorizem sentido dessas práticas culturais, e juntos com pais e sociedade para que juntos possamos reverter 
essa situação. ” (POF II)

Fonte: As autoras (2019)

A dificuldade ortográfica presente no aprendizado das crianças refere muito as irregularidades contextuais, ou seja, são aquelas que as palavras possuem o mesmo som. Dessa forma, os resultados obtidos demonstram que é preciso colocar cada vez mais a leitura na vida do aprendiz, pois dessa forma saberão decifrar as palavras corretamente conforme aponta Morais (2009), para esse tipo de dificuldade ortográfica, há regras subjacentes que devem ser explicitadas.

As irregularidades que aparecem, como outra dificuldade, referem ao sistema ortográfico, Morais (2009) apontam que as dificuldades relacionadas a arbitrariedades dos sistemas linguísticos serão entendidas se o aluno tiver imagem fotográfica das palavras que apresentam irregularidades ortográficas. Assim, o contato com materiais impressos, para esse autor, faz-se necessário para a memorização de tais grafias.

Segundo ele, ter o contato com materiais impressos ajuda a ter boas reflexões sobre as dificuldades ortográficas, pois assim pode ser um grande mediador do professor. Para que o aluno minimize essas grandes dificuldades é preciso não pular etapas, ter interesse e ter a leitura como uma grande companheira, mas acima de tudo que os pais possam desenvolver junto com os filhos para conseguirem um melhor desenvolvimento. Desse modo, as respostas dos docentes presentes no quadro 1, apontam essas lacunas no tocante à produção de textos e desvios ortográficos.

\section{Considerações finais}

A ortografia se apresenta como a maior dificuldade na produção de textos dos alunos, por isso é ressaltado a importância de um ensino reflexivo a respeito da ortografia, a fim deque os alunos possam de fato absorver suas regras e obter êxito na apropriação do sistema ortográfico. Concluiu-se ainda que faz se necessária uma demanda muito grande de aprendizes que não dominam o processo de leitura e escrita no $5^{\circ}$ ano do ensino Fundamental, porém mostra 
também que há professores que não dão a devida importância ao fracasso escolar do aluno (desvios ortográficos), diante do aspecto elementar, no entanto, de primeira importância que o domínio desses dois saberes, base para todos os outros aspectos da aprendizagem que virão.

Acredita-se ser fundamental que o professor tenha domínio do sistema ortográfico de forma que entenda os erros de seus alunos para elaboração de atividades para minimizá-las. Assim, compreende e pode estabelecer diferentes estratégias de ensino e aprendizagem, para que os aprendizes se apropriem das regularidades e irregularidades presentes no sistema ortográfico.

Desse modo, é necessário que busquem alternativas de aprendizagem além do trabalho realizado em sala de aula, de acordo com o nível de não assimilação apresentado pelo aluno com relação à ortografia.

O saber ler e escrever tem um papel fundamental na vida do cidadão. Com o hábito de ler e escrever, o educador com certeza obtém resultados positivos no desempenho do seu trabalho, em especial pode contribuir com a melhoria do processo ensino aprendizado daqueles que estão sob sua tutela.

\section{Referências bibliográficas}

\section{BRASIL. Parâmetros Curriculares Nacionais: Língua}

Portuguesa. Brasília, 1997.

CARNEIRO, Agostinho Dias. Redação em construção. A escrita do texto. 2. Ed. rev. e ampl. São Paulo: Moderna, 2001.

COLELlO. Silvia M. Gasparian. A escola que (não) ensina a escrever (Paz terra, 2004)

GARCIA, Othon Moacyr. Comunicação em prosa moderna. 21 ed. Rio de Janeiro: Fundação Getúlio Vargas, 2002.

GOLDENBERG, M. A arte de pesquisar. Rio de Janeiro: Record, 1997.

KOCK, Ingedore Villaça. O texto é a construção dos sentimentos. São Paulo: Contexto, 1998. 
MORAIS, Artur Gomes. O aprendizado da ortografia. Belo Horizonte: Autentica 2003.

MORAIS, Artur Gomes. Ortografia se aprende desde cedo. Nova Escola, jan./fev. 2003.

PILASTRI, Paula Regina. A importância da escrita. 2009. Disponível em http://www.administradores.com.bracessado em 20 de nov. de 2015.

SOARES, Magda. Linguagem e Escola, uma perspectiva social. São Paulo, Ática, 1986.

SILVA, Arlete Vidal dos santos. Produção escrita e dificuldades ortográficas. Edição. Itamari-BA: Editora, 2009.

TEBEROSK, Ana. Uma experiência em ensinar e aprender linguagem escrita. Leitura e vida, v.29, n.4, p.6-19, 2008. 